\title{
Article \\ Low-Temperature Plasma as an Approach for Inhibiting a Multi-Species Cariogenic Biofilm
}

\author{
Leandro W. Figueira ${ }^{1,2}$, Beatriz H. D. Panariello ${ }^{2}$, Cristiane Y. Koga-Ito ${ }^{1}\left(\right.$ and Simone Duarte ${ }^{2, *}$ \\ 1 Department of Environmental Engineering and Oral Biopathology Graduate Program, \\ Institute of Science and Technology, São Paulo State University, UNESP, São José dos Campos, \\ São Paulo 12.245-000, Brazil; lefiguei@iu.edu (L.W.F.); cristiane.koga-ito@unesp.br (C.Y.K.-I.) \\ 2 Department of Cariology, Operative Dentistry and Dental Public Health, \\ Indiana University School of Dentistry, Indianapolis, IN 46202, USA; bpanari@iu.edu \\ * Correspondence: siduarte@iu.edu
}

check for updates

Citation: Figueira, L.W.; Panariello, B.H.D.; Koga-Ito, C.Y.; Duarte, S. Low-Temperature Plasma as an Approach for Inhibiting a Multi-Species Cariogenic Biofilm. Appl. Sci. 2021, 11, 570. https:// doi.org/10.3390/app11020570

Received: 8 December 2020 Accepted: 31 December 2020 Published: 8 January 2021

Publisher's Note: MDPI stays neutral with regard to jurisdictional clai$\mathrm{ms}$ in published maps and institutional affiliations.

Copyright: (C) 2021 by the authors. Licensee MDPI, Basel, Switzerland. This article is an open access article distributed under the terms and conditions of the Creative Commons Attribution (CC BY) license (https:// creativecommons.org/licenses/by/ $4.0 /)$.
Featured Application: Low exposure times of low-temperature plasma (LTP) affects single- and multi-species cariogenic biofilms, which makes it a promising candidate to contribute to the development of new protocols for the treatment and control of dental caries.

Abstract: This study aimed to determine how low-temperature plasma (LTP) treatment affects single- and multi-species biofilms formed by Streptococcus mutans, Streptococcus sanguinis, and Streptococcus gordonii formed on hydroxyapatite discs. LTP was produced by argon gas using the kINPen09 ${ }^{\mathrm{TM}}$ (Leibniz Institute for Plasma Science and Technology, INP, Greifswald, Germany). Biofilms were treated at a $10 \mathrm{~mm}$ distance from the nozzle of the plasma device to the surface of the biofilm per $30 \mathrm{~s}, 60 \mathrm{~s}$, and $120 \mathrm{~s}$. A $0.89 \%$ saline solution and a $0.12 \%$ chlorhexidine solution were used as negative and positive controls, respectively. Argon flow at three exposure times (30 s, 60 s, and $120 \mathrm{~s}$ ) was also used as control. Biofilm viability was analyzed by colony-forming units (CFU) recovery and confocal laser scanning microscopy. Multispecies biofilms presented a reduction in viability $\left(\log _{10} \mathrm{CFU} / \mathrm{mL}\right)$ for all plasma-treated samples when compared to both positive and negative controls $(p<0.0001)$. In single-species biofilms formed by either $S$. mutans or $S$. sanguinis, a significant reduction in all exposure times was observed when compared to both positive and negative controls $(p<0.0001)$. For single-species biofilms formed by $S$. gordonii, the results indicate total elimination of $S$. gordonii for all exposure times. Low exposure times of LTP affects single- and multi-species cariogenic biofilms, which indicates that the treatment is a promising source for the development of new protocols for the control of dental caries.

Keywords: antibacterial; dental caries; Streptococcus mutans; Streptococcus gordonii; Streptococcus sanguinis

\section{Introduction}

Even though dental caries have become less prevalent in developed countries and are delimited to some sectors of the population [1], it is still prevalent in underdeveloped countries, especially in children up to six years of age [2-4]. Dental caries are caused by a combination of factors, including the frequent consumption of sucrose combined with a dental biofilm composed of acid-producing microorganisms [5,6]. The cariogenic dental biofilm is formed by highly organized diverse microbial communities enmeshed in a polysaccharide-rich matrix and adheres to the dental surface [7]. The microbial community is linked to a chain of interactions that can regulate pathogenicity and resistance to antibiotics [8]. The extracellular matrix can function as the first line of defense against the effect of antibiotics and for the transfer of genes among microorganisms [9]. Microorganisms in the biofilm can be up to a thousand times more resistant to antibiotics when compared to free-floating cells [10]. The formation of the cariogenic biofilm is an ongoing process with 
numerous stages. First, the acquired pellicle is formed, followed by the primary colonization, later proliferation of adhered microorganisms, secondary co-aggregation, and finally the biofilm maturation process [11]. For disease progression to occur, microorganisms need a source of carbohydrates from the diet, exposure time to acidic $\mathrm{pH}$, and a susceptible host. Oral bacteria ferment these carbohydrates, producing acids, thus beginning the disease stage. Thereafter, acid-producing and low-pH-tolerant bacteria begin to increase their population within the acidic environment, causing demineralization of the tooth surface and, eventually, the formation of cavities [12-15].

Sucrose is a cariogenic carbohydrate obtained from the diet capable of stimulating biochemical and physiological changes in oral biofilm. Moreover, carbohydrates can alter the formation of the cariogenic biofilm. Carbohydrates may also change the phenotype during the formation of the cariogenic biofilm [16,17]. The $\mathrm{pH}$ reduction causes a selection of acidophilic and acidogenic microorganisms, which results in an even more cariogenic environment [18]. In addition, sucrose can participate as the substrate for extracellular polysaccharides production [19]. Some studies have proven the ability of sucrose to reduce concentrations of calcium $(\mathrm{Ca})$, inorganic phosphorus $(\mathrm{Pi})$, and fluoride $(\mathrm{F})$ in oral biofilms [20]. These ions are of crucial importance and are linked to the remineralization of enamel and dentin [20,21].

Streptococci make up more than $80 \%$ of the initial constituents of biofilm and are responsible for the initial colonization process. S. sanguinis and S. gordonii are amongst the initial species to inhabit the dental surface [22]. These microorganisms can express adhesin molecules on the cell surface with binding capabilities [23]. Furthermore, they are capable of adhering through their fimbria in the saliva-coated hydroxyapatite layer [24]. For this reason, they compete for attaching to the same receptors offered by the host [23]. The development of caries may be associated with the growth of $S$. mutans and lactobacilli, as well as a decrease in the general diversity of other species that colonize the oral cavity [25-27]. Interactions between species of oral streptococci can play a significant part in this change. When in large quantities in dental biofilm, some streptococci may have a beneficial characteristic capable of antagonizing S. mutans [28]. This antagonism can be demonstrated when these microorganisms are identified and listed by molecular identification methods, which allows greater clarity in the study of the microbiota associated with dental caries [28]. An in vitro experiment using molecular biology techniques demonstrated this antagonism, indicating that $S$. sanguinis and $S$. gordonii are directly involved with $S$. mutans for dominance over a given niche [19]. While $S$. mutans is not considered an early colonizer, it has unique mechanisms to metabolize carbohydrates, which results in acids and generate an adherent extracellular polysaccharide matrix involved in the progress of dental caries [29].

Another important fact to question is how we can improve the current protocols existing today in the treatment of dental caries. In this sense, minimally invasive dentistry (MID) has been presented as an alternative treatment for dental caries disease. MID aims to control or paralyze disease activity using non-operative (non-invasive) techniques that prevent unnecessary tissue loss and cause less damage to the dentin pulp complex [30-32] Recently, plasma therapy has been suggested as a potential therapeutic tool in the treatment of dental caries due to its antimicrobial efficacy against cariogenic bacteria $[33,34]$.

Plasma is considered the fourth state of matter, consisting of a mixture of atoms, molecules, and ions at different densities and temperatures. It is conductive and responds to electric and magnetic fields [35]. Plasma is produced by applying an electric field to noble or molecular gases, such as argon, helium, oxygen, and nitrogen [36-38]. Cold plasmas that reach temperatures below $40{ }^{\circ} \mathrm{C}$ are known as biologically viable sources of energy $[36,38]$. In addition, plasma can be generated under different pressures. Biologically applied cold plasmas are produced at atmospheric pressure and are named cold atmospheric pressure plasmas [39]. Among different types of plasmas, low-temperature plasma (LTP) is the most promising for biomedical applications.

Delben et al. [40] determined the effects of LTP on mono- and dual-species biofilms composed by Candida albicans and Staphylococcus aureus. Biofilms were exposed to LTP 
for $60 \mathrm{~s}$, and all plasma-treated biofilms showed a significant reduction in comparison to the negative control. Furthermore, LTP showed low cytotoxicity based on a test with reconstituted oral epithelium [40]. Chiodi et al. [41] reported that LTP reduced the viability of C. albicans biofilms after 5 min of LTP exposure, with low cytotoxicity to Vero cells. In the same study, LTP was used to treat experimentally induced oral candidiasis and the histological analysis showed a remarkable decrease in candidal tissue invasion [41]. The effect of LTP on Porphyromonas gingivalis biofilm grown on titanium discs was also reported [42]. After $1 \mathrm{~min}$ and $3 \mathrm{~min}$ of treatment, a significant reduction in P. gingivalis viability was observed when compared to the negative control. Moreover, low toxicity to cells of the gingival epithelium was observed in the same study [42]. Another study demonstrated that $S$. mutans sown on the agar plates can be inactivated by needle LTP [43]. Culture of $S$. mutans that was sown on the agar surface was treated with plasma. After plasma application and incubation, a spatially resolved biological diagnosis was performed, and the pattern of the bacterial colonies present in the sample was photographed. The images of this biological diagnosis revealed that $S$. mutans was killed in a solid circle of $5 \mathrm{~mm}$ diameter, showing that a precise treatment of the site is possible [43].

Experiments were conducted to test the sterilizing capability of LTP against oral microorganisms (Streptococcus mutans, Candida albicans, and Enterococcus faecalis) to translate its potential for clinical application by a direct exposure test on a solid surface, indirect exposure test in a liquid phase, and inhibitory test of reactive oxygen species (ROS) [44]. This study showed that the LTP jet inactivates oral microorganisms present in both solid and liquid phases and that ROS influenced this sterilization effect [44].

Thus, considering the effect of LTP on a different range of oral biofilms, and the potential therapeutic effect on oral diseases, the goal of this present study was to determine how LTP treatment at different exposure times affects single and multi-species cariogenic biofilms formed by S. mutans, S. gordonii, and S. sanguinis. In the present work, multispecies biofilms of $S$. sanguinis, S. gordonii, and S. mutans were treated with low-temperature plasma (LTP). To date, there are no available data regarding the formation of a multi-species cariogenic biofilm composed of these three streptococci and subsequent treatment with LTP jet under atmospheric pressure.

\section{Materials and Methods}

\subsection{Plasma Device and Parameters}

Low-temperature plasma (LTP) was generated using argon (AR) gas with the device kINPen09 ${ }^{\mathrm{TM}}$ (Leibniz Institute for Plasma Science and Technology, INP, Greifswald, Germany) [45]. The device (Figure 1) comprised a hand-held unit (170 $\mathrm{mm}$ in length, $20 \mathrm{~mm}$ in diameter, and $170 \mathrm{~g}$ ) that generated a plasma jet, a DC power supply (system power: $8 \mathrm{~W}$ at $220 \mathrm{~V}, 50 / 60 \mathrm{~Hz}$ ), and a gas supply unit. The LTP jet was produced from the top of the central electrode and expanded to the surrounding air outside the nozzle [45]. Biofilms formed on the top of hydroxyapatite discs (Clarkson Chromatography Products, Inc., South Williamsport, PA, USA) were treated with a distance of $10 \mathrm{~mm}$ from the biofilm surface to the tip of the plasma device for $30 \mathrm{~s}, 60 \mathrm{~s}$, and $120 \mathrm{~s}$ of exposure in continuous working mode [45]. A support developed by the laboratory collaborators and a calibrated operator trained to conduct the experiment in a consistent approach was used to guarantee the standardization of the distance between the plasma tip and the sample. The specimens were moved horizontally using sterile tweezers during LTP application to scan the whole surface. Argon gas flow was set to $5 \mathrm{slm}$, and the flow rate was controlled using a flow controller (MKS Instruments, München, Germany). 


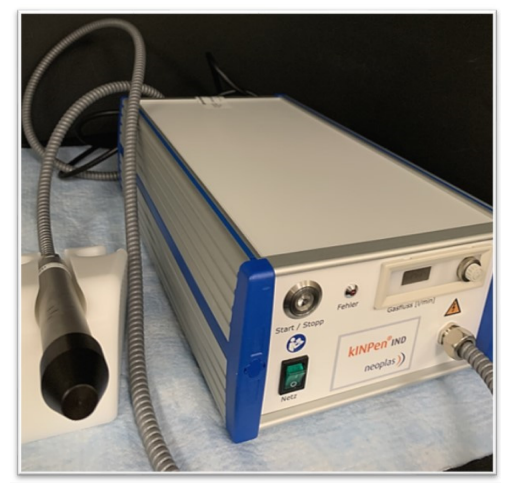

Figure 1. Low-temperature plasma (LTP) device kINPen09 ${ }^{\mathrm{TM}}$ (Leibniz Institute for Plasma Science and Technology, INP, Greifswald, Germany).

\subsection{Microorganisms}

S. mutans UA159 (ATCC 700610), S. gordonii (ATCC 10558), and S. sanguinis (ATCC 10556) strains were used to form single- or multi-species biofilms. Growth curves were performed to standardize the inoculum for the biofilm, and the equivalent colony-forming units (CFU) were determined. Stock cultures were maintained at $-80^{\circ} \mathrm{C}$, reactivated onto a specific medium (BD BBL ${ }^{\text {TM }}$ CDC anaerobe 5\% sheep blood agar, Becton, Dickinson and Company, Sparks, Maryland 21152, USA), and incubated at $37^{\circ} \mathrm{C}$ for $48 \mathrm{~h}$. After that, for the formation of the pre-inoculum, 10 isolated colonies were collected with the aid of a sterile loop and subsequently transferred to a centrifuge tube containing $50 \mathrm{~mL}$ of tryptic soy broth (TSB) supplemented with $1 \%$ glucose at $37^{\circ} \mathrm{C}, 5 \% \mathrm{CO}_{2}$ for $18 \mathrm{~h}$. Then, $1 \mathrm{~mL}$ of the pre-inoculum was transferred to a centrifuge tube containing $9 \mathrm{~mL}$ of TSB supplemented with $1 \%$ glucose. The same procedures were done for all microorganisms separately. The growth of microorganisms was monitored aseptically every hour ( $0-24 \mathrm{~h}$ ) by employing subsequent absorbance readings (optical density) in a spectrophotometer using the $600 \mathrm{~nm}$ wavelength to ensure the reproducibility of the biofilm model.

\subsection{Single- and Multi-Species Cariogenic Biofilm}

Single- and multi-species biofilms composed by S. mutans, S. gordonii, and S. sanguinis were formed as previously described [46], with modifications. Microorganisms were activated on anaerobe $5 \%$ sheep blood agar and incubated for $48 \mathrm{~h}$. To prepare the preinoculum, the microorganisms were transferred separately from the agar plate to a centrifuge tube containing $10 \mathrm{~mL}$ of TSB (Becton Dickinson France SA, Le Pont de Claix, France) supplemented with $1 \%$ glucose. Tubes were incubated at $37^{\circ} \mathrm{C}$ in $5 \% \mathrm{CO}_{2}$ for $18 \mathrm{~h}$. Then, $1 \mathrm{~mL}$ of the pre-inoculum was transferred to another tube containing TSB supplemented with $1 \%$ sucrose and incubated for $6 \mathrm{~h}$, corresponding to $10^{8} \mathrm{CFU} / \mathrm{mL}$ of each microorganism. The suspensions were standardized in a spectrophotometer to confirm the number of microorganisms after $6 \mathrm{~h}$ of growth. Suspensions were diluted to $8 \times 10^{6} \mathrm{CFU} / \mathrm{mL}$ according to Arthur et al. [12]. The same procedures were performed for each microorganism separately. For the multi-species biofilms, an equal part of each standardized suspension was deposited in a sterile centrifuge tube, and the suspension was homogenized using a vortex. For single- and multi-species biofilms, the microorganism's suspensions were added to the wells of 24-well plates containing sterile hydroxyapatite discs [13]. For each well, $200 \mu \mathrm{L}$ of the single- or multi-species inoculum and $800 \mu \mathrm{L}$ of TSB broth supplemented with $0.2 \%$ sucrose were added. To find the ideal concentration of sugar in which all the three strains (S. mutans, S. gordonii, and S. sanguinis) would be recovered after $48 \mathrm{~h}$ of biofilm growth, preliminary tests were conducted using concentrations of $0.2 \%, 0.5 \%, 0.75 \%$, and $1 \%$ sucrose. The best sucrose concentration in which all microorganisms could be recovered was $0.2 \%$. Biofilms were then formed for $48 \mathrm{~h}$, and fresh culture medium was replaced after $24 \mathrm{~h}\left(37^{\circ} \mathrm{C}, 5 \% \mathrm{CO}_{2}\right)$ [46]. 


\subsection{LTP Treatment and Biofilm Processing}

After $48 \mathrm{~h}$ of biofilm formation, single- and multi-species biofilms were treated with LTP and flow control (argon gas) for $30 \mathrm{~s}, 60 \mathrm{~s}$, and $120 \mathrm{~s}$. The positive control (PC) chosen for the study was chlorhexidine (C9394, Sigma-Aldrich, St. Louis, MO, USA), which is a gold-standard antiseptic commonly used as an anti-plaque mouthwash. Biofilm samples were dipped in a well containing $1 \mathrm{~mL}$ of $0.12 \%$ chlorhexidine (PC) for $1 \mathrm{~min}$. For the negative control (NC), a $0.89 \% \mathrm{NaCl}$ solution was applied for the same amount of time. The total number of treated samples for each group was $9(n=9)$, and assays were performed on three different occasions (three triplicates). The biofilms were scratched from the top of the hydroxyapatite discs using a sterile spatula and diluted in $5 \mathrm{~mL}$ of sterile $0.89 \%$ $\mathrm{NaCl}$ solution. Biofilm suspension was sonicated for $10 \mathrm{~s}$ pulses at an output of $9 \mathrm{~W}$ (Sonic Dismembrator model 100, Thermo Fisher Scientific, Waltham, Massachusetts, USA). The same procedures were performed for each experimental group and controls. The obtained suspensions were serially diluted and plated on blood agar (BD BBL ${ }^{\mathrm{TM}} \mathrm{CDC}$ anaerobe $5 \%$ sheep blood agar). After incubation in $5 \% \mathrm{CO}_{2}$ at $37^{\circ} \mathrm{C}$ for $48 \mathrm{~h}$, the numbers of $\mathrm{CFU} / \mathrm{mL}$ of recovered S. mutans, S. gordonii, and S. sanguinis from the biofilm were recorded.

\subsection{Confocal Laser Scanning Microscopy (CLSM) of Single- and Multi-Species Biofilm}

Multi-species biofilms composed by S. mutans, S. gordonii, and S. sanguinis (formed as described in Section 2.3) were stained with LIVE/DEAD ${ }^{\circledR}$ BacLight $^{\mathrm{TM}}$ Bacterial Viability Kit (L13152; Molecular Probes, Inc., Thermo Fisher Scientific, Waltham, MA, USA) and incubated in the dark at room temperature for $15 \mathrm{~min}$ to allow penetration of the fluorophores inside the bacterial cells. Specimens were then washed twice with $0.89 \% \mathrm{NaCl}$ solution and examined under a Leica SP8 Resonant-scanning confocal/multiphoton microscope using Leica Fluotar VISIR 25x/0.95 water objective (Leica Microsystems, Wetzlar, Germany), with a free working distance of $2.3 \mathrm{~mm}$. Serial sessions on the XYZ plane were observed.

\subsection{Statistical Analysis}

The Shapiro-Wilk test was used to verify the data's normal distribution, and homogeneity of variance was confirmed by the Levene test $(\alpha=0.05)$. Analyses were performed using IBM SPSS statistical software package (version 25) for Windows (IBM Corp., New York, NY, USA). Results are in mean values ( \pm standard deviation), being analyzed by Analysis of Variance (ANOVA) and Tukey's post hoc test, considering $\alpha=0.05$. GraphPad Prism 5.0 for Windows (GraphPad Software, La Jolla, CA, USA, www.graphpad.com) was used to analyze the data.

\section{Results}

\subsection{Single-Species Biofilms}

Figure 2 shows the results for single-species biofilms formed by $S$. mutans. For the LTP-treated groups, a significant reduction in all exposure times $(p<0.0001)$ was observed when compared to both negative and positive controls, and there was no statistically significant difference between the exposure to LTP for $60 \mathrm{~s}$ and $120 \mathrm{~s}(p>0.05)$. Figure 3 shows the results obtained for single-species biofilms formed by S. gordonii. No S. gordonii CFUs were recovered in the biofilms after treatment with plasma in all of the tested exposure times. Figure 4 shows the results obtained for single-species biofilms formed by S. sanguinis. Treatment with LTP for the three exposure times significantly reduced biofilm viability when compared to the negative and positive controls $(p<0.0001)$, and the effect was proportional to the increase in exposure time. For all the single-species biofilms, the negative and positive controls were not statistically different from each other $(p \geq 0.05)$ 


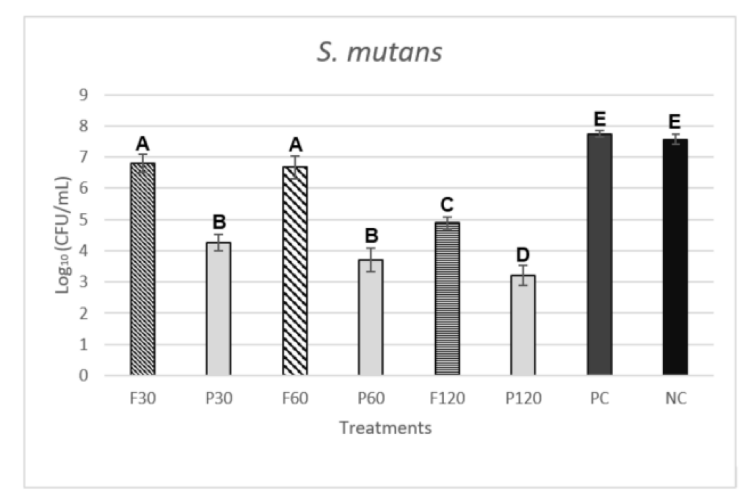

Figure 2. Mean values and standard deviations $\log _{10} \mathrm{CFU} / \mathrm{mL}$ of single-species biofilms composed of S. mutans treated with LTP, $0.12 \%$ chlorhexidine (positive control), or $0.89 \%$ saline solution (negative control). Different letters indicate significant statistical difference ( $\mathrm{n}=9 ; p \leq 0.05$; Analysis of Variance, ANOVA, Tukey's test). F30, F60, and F120 (argon gas-flow control treatment for $30 \mathrm{~s}, 60 \mathrm{~s}$, and 120 s); P30, P60, and P120 (LTP treatment for 30 s, 60 s, and 120 s); PC (positive control); and NC (negative control).

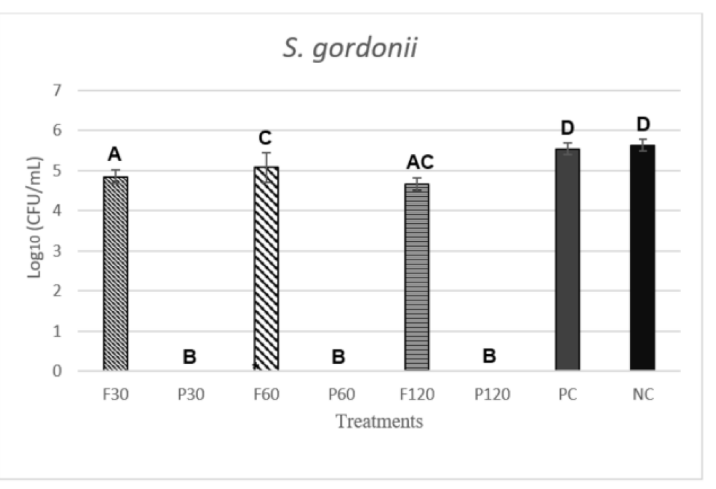

Figure 3. Mean values and standard deviations $\log _{10} \mathrm{CFU} / \mathrm{mL}$ of single-species biofilms composed of S. gordonii treated with LTP, $0.12 \%$ chlorhexidine (positive control), or $0.89 \% \mathrm{NaCl}$ solution (negative control). Different letters indicate significant statistical difference ( $\mathrm{n}=9 ; p \leq 0.05$; ANOVA, Tukey's Test). F30, F60, and F120 (argon gas-flow control treatment for $30 \mathrm{~s}, 60 \mathrm{~s}$, and $120 \mathrm{~s}$ ); P30, P60, and P120 (LTP treatment for 30 s, 60 s, and 120 s); PC (positive control); and NC (negative control).

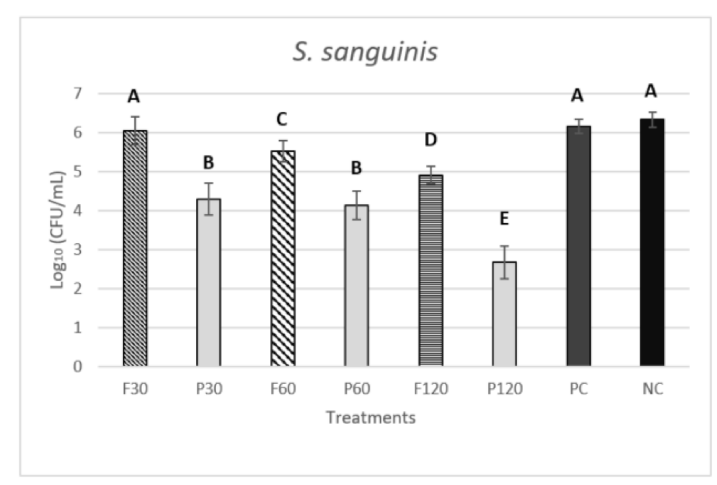

Figure 4. Mean values and standard deviations $\log _{10} \mathrm{CFU} / \mathrm{mL}$ of single-species biofilms composed of S. sanguinis treated with LTP, $0.12 \%$ chlorhexidine (positive control), or $0.89 \%$ saline solution (negative control). Different letters indicate significant statistical difference ( $\mathrm{n}=9 ; p \leq 0.05$; ANOVA, Tukey's Test). F30, F60, and F120 (argon gas-flow control treatment for 30 s, 60 s, and 120 s); P30, P60, and P120 (LTP treatment for 30 s, 60 s, and 120 s); PC (positive control); and NC (negative control). 


\subsection{Multi-Species Biofilm}

Figure 5 shows the $\log _{10} \mathrm{CFU} / \mathrm{mL}$ results for the multi-species biofilms formed by S. mutans, S. gordonii, and S. sanguinis. A significant $\log _{10} \mathrm{CFU} / \mathrm{mL}$ reduction was observed in all plasma-treated samples in comparison to the negative and positive controls $(p<0.0001)$ for the recovery of the three tested microorganisms. For S. mutans, recovered from the multi-species biofilm, no statistically significant difference was observed in the group treated with argon gas flow for $30 \mathrm{~s}$ compared to the positive and negative control groups $(p=0.0054,0.0031)$. LTP treated biofilms showed significant $\log _{10} \mathrm{CFU} / \mathrm{mL}$ reduction in all exposure times in comparison to the negative and positive controls $(p<0.0001)$. There was no recovery of $S$. gordonii after treatment with LTP in all of the tested exposure times, which indicates that LTP treatment eliminated S. gordonii in the tested model. In contrast to the results from single-species biofilms, there was also no recovery of $S$. sanguinis after LTP exposure for $30 \mathrm{~s}, 60 \mathrm{~s}$, and $120 \mathrm{~s}$, which indicates that LTP treatment also eliminated S. sanguinis in the tested model.

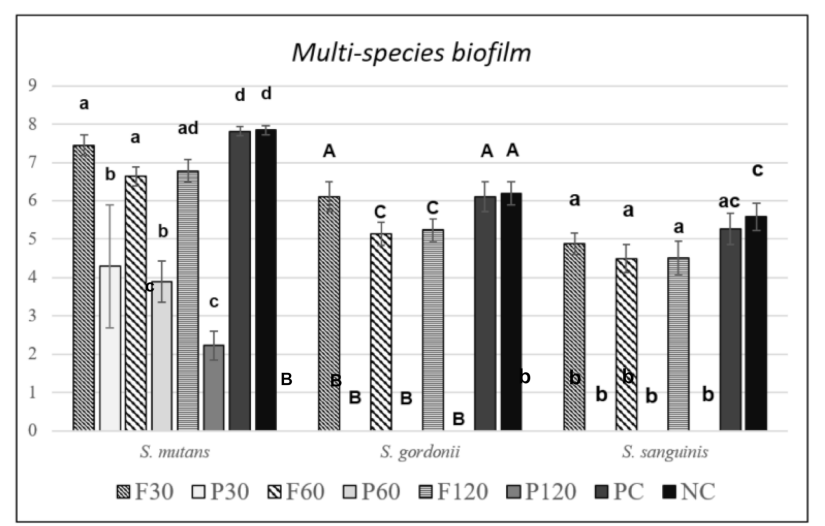

Figure 5. Mean values and standard deviations $\log _{10} \mathrm{CFU} / \mathrm{mL}$ of multi-species biofilms formed by S. mutans, S. gordonii, and S. sanguinis, chlorhexidine (positive control), or $0.89 \% \mathrm{NaCl}$ solution (negative control). Different letters indicate significant statistical difference $(n=9 ; p \leq 0.05$; ANOVA, Tukey's Test). F30, F60, and F120 (argon gas-flow control treatment for 30 s, 60 s, and 120 s); P30, P60, and P120 (LTP treatment for 30 s, 60 s, and 120 s); PC (positive control); and NC (negative control).

\subsection{Confocal Scanning Laser Microscopy (CSLM)}

To demonstrate the effect of LTP treatment, Figure 6 presents the confocal scanning laser microscopy (CSLM) representative images, which show the morphology and structural organization of multi-species biofilm after treatment with LTP for the highest tested exposure time (120 s) or exposed to the negative control. The images show live cells, which are stained green (SYTO 9), and dead cells, which are stained red (propidium iodide). Samples treated with LTP for $120 \mathrm{~s}$ present a visually larger area covered in dead cells when compared to the negative control, which can be visualized in the overlaid images (P120 live/dead).
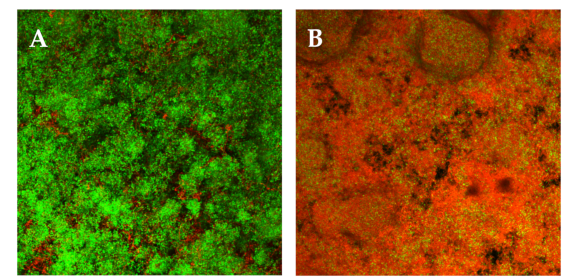

Figure 6. Confocal laser scanning microscopy (CLSM) of multi-species biofilms formed by S. mutans, S. gordonii, and S. sanguinis exposed to the negative control or treated with LTP for $120 \mathrm{~s} ; 25 \mathrm{X} 0.95$ zoom. Biofilms are stained with Live/Dead BacLight Viability kit. Live cells are in fluorescent green (SYTO 9) and dead cells in fluorescent red (propidium iodide). (A) Negative control (NC), live/dead overlaid images and (B) LTP for $120 \mathrm{~s}$ (P120, live/dead overlaid images). 


\section{Discussion}

Dental caries can cause partial or total destruction of dental hard tissues by (acidic) byproducts of biochemical processes in the fermentation of carbohydrates from the diet [15,47]. It also relies on microorganisms and other host factors, such as dental surface [47]. Dental caries is considered a biofilm-dependent disease [48]. Dental biofilm is a highly organized polymicrobial structure embedded in an extracellular matrix formed by extracellular exopolysaccharides (EPS) [49,50]. In this study, different species that are commonly related to the formation of the cariogenic biofilm on the tooth surface were used.

The results of this study show that multi-species cariogenic biofilm treated with LTP had a significant $\log _{10} \mathrm{CFU} / \mathrm{mL}$ reduction in all plasma-treated samples compared to when exposed to the negative and positive controls. A previous study that treated $S$. mutans and S. sanguinis dual-species biofilms formed on the bottom of polystyrene plates with atmospheric non-thermal argon/oxygen plasma for $120 \mathrm{~s}$ observed a reduction of $99 \%$ of viable cells when compared to their exposure to the negative control [51]. Our results corroborate this previous report because a significant reduction in the viability of a multi-species biofilm formed by S. mutans, S. gordonii, and S. sanguinis was detected after exposure to LTP for as low as $30 \mathrm{~s}$.

Argon gas was the choice for the plasma-generating device; the distance from the plasma outlet to the sample surface was $10 \mathrm{~mm}$; and the biofilms were treated for $30 \mathrm{~s}$, $60 \mathrm{~s}$, and $120 \mathrm{~s}$. Hirano et al. [52] analyzed the effect of a plasma-generating laboratorydeveloped device, which was different from the one used in our work, on free-floating planktonic cells. Bacterial cell suspensions containing $10^{7} \mathrm{CFU} / \mathrm{mL}$ of either S. mutans, Porphyromonas gingivalis, or E. faecalis were treated. The treatment with LTP caused a significant reduction of more than $4 \operatorname{logs}$ in the number of $S$. mutans after 3 min of treatment, and almost all the bacteria were killed after $5 \mathrm{~min}$. The gas used in their study was compressed air with a pulsed energy generator. The distances of $1 \mathrm{~mm}, 3 \mathrm{~mm}$, and $5 \mathrm{~mm}$ were set between the plasma outlet and the single-species $S$. mutans biofilm surface, and the samples were treated for 1,3,5, and $7 \mathrm{~min}$ [52].

Remarkably, in our study, in addition to using a greater distance from the output of the plasma device to the surface of the sample and less time of exposure, we treated a multi-species biofilm, which is known to be more resistant to anti-biofilm therapies than single-species biofilms [10]. Furthermore, there was no recovery for S. gordonii $\log _{10}$ CFU / mL after treatment with LTP in all exposure time tested in this work for both single- and multi-species biofilms. S. gordonii is one of the early stage colonizers of the oral cavity that can bind directly to salivary proteins on the tooth surface, establishing a basis for the construction of microbial communities of the cariogenic biofilm $[53,54]$. The reduction of these microorganisms in the oral cavity can impair the formation of the cariogenic biofilm.

Argon plasma produced by kINPen09 ${ }^{\mathrm{TM}}$ was also reported as a treatment option for biofilms formed by $S$. sanguinis, where the biofilms were grown in a European biofilm reactor (EUREBI) as well as in 24-well plates [55]. For both biofilms formed in the different model systems, substrate for biofilm formation was the surface of titanium plates and the number of CFU were determined at $0,24,48$, and $72 \mathrm{~h}$ (per exposure time). Using this model, the authors defined that, after $72 \mathrm{~h}$, a mature biofilm was established. They concluded based on this study that EUREBI was the most effective system. Subsequently, biofilms were treated with a plasma jet for $180 \mathrm{~s}$ at $10 \mathrm{~mm}$ of distance between the top of the disc and the plasma source. The work showed a significant reduction $\left(0.6 \log _{10} \mathrm{CFU} / \mathrm{mL}\right.$ or $0.5 \log _{10} \mathrm{CFU} / \mathrm{mL}$ ) in biofilms compared to the control in either the EUREBI produced biofilm model or in 24-well plates [55]. The methodology we used uses hydroxyapatite discs as the substrate for biofilm formation, which closely represents the tooth mineral. Our results indicate that, for the treatment of multi-species biofilms formed on a hydroxyapatite disc surface, and treated with LTP for $30 \mathrm{~s}, 60 \mathrm{~s}$, and $120 \mathrm{~s}$ at a $10 \mathrm{~mm}$ distance from the tip of the plasma to the sample, S. sanguinis was not recovered. For single-species biofilms formed by the same microorganism, there was CFU recovery of S. sanguinis after 
LTP treatment with significant CFU reduction observed in all tested exposure times when compared to their exposure to the positive and negative controls. S. sanguinis is typically associated with the formation of the cariogenic biofilm in the oral cavity $[56,57]$. Like S. gordonii, S. sanguinis is a pioneer colonizer that is closely related to the further binding of other microorganisms on the tooth surface and subsequent development of a mature cariogenic biofilm $[25,58]$.

Chlorhexidine is a gold-standard antiseptic [59] that was chosen as a positive control for the present study. However, a single treatment with $0.12 \%$ chlorhexidine, as expected, is not able to reduce the CFU amount when compared to the negative control on both singleand multi-species biofilms. However, as a mouthwash, $0.12 \%$ chlorhexidine is used twice daily as an anti-plaque agent for oral infections due to its effectiveness in reducing bacteria present in the saliva and on the tongue $[60,61]$.

The low efficacy of a single treatment of chlorhexidine on mature biofilms $[62,63]$ is associated with the resistance that a well-established and mature biofilm presents, which protects the microorganisms against desiccation, oxidizing, or charged biocides, some antibiotics, and metallic cations, ultraviolet radiation, some protozoan grazers, and host immune defenses [64].

Plasmas produce electromagnetic radiation, such as ultra-violet radiation and light in the visible spectrum, and comprise excited gas particles, charged ions, free electrons, free radicals, neutral reactive oxygen (ROS) and nitrogen species (RNS), and molecule fragments. LTP-reactive species are rapidly produced and are good sources of reactive oxygen and nitrogen species including singlet oxygen, ozone, hydroxyl radicals, nitrous oxide, and nitrogen dioxide [65]. The antibacterial effects of LTP mediated by ROS have not been demonstrated to increase bacterial resistance when bacteria are continuously exposed to it. Plasmas can reach good gas-phase chemistry deprived of high gas temperatures. This happens because plasmas display much higher electron energies than that of the ions and the neutral species. The energetic electrons collide with the background gas, producing higher dissociation, excitation, and ionization levels. Since ions and neutrals continue to be quite cold, as there is no contact thermal damage caused by the plasma [65]. The unique characteristics of LTP have opened a new era in dental care. Even though this study has limitations, such as the lack of analysis of the action of LTP in biofilm formed in situ and the absence of more complex cytotoxicity tests, it has shown promising results in oral biofilm-related disease. Dental treatments with LTP are painless and drill-less, thus making them patient-friendly. These findings indicate that LTP is potentially a good candidate for future clinical treatments [65].

\section{Conclusions}

Low-temperature plasma showed significant antibiofilm effect against single-and multi-species biofilms formed by S. mutans, S. gordonii, and S. sanguinis, eliminating S. gordonii in both single- and multi-species biofilms and S. sanguinis in the multi-species biofilm. The biofilm model used in this work is representative of an oral cariogenic biofilm containing two species (S. gordonii and S. sanguinis) that are critical on initial colonization of the dental surface. Both microorganisms were inactivated (approximately $6.2 \log _{10} \mathrm{CFU} / \mathrm{mL}$ and $5.5 \log _{10} \mathrm{CFU} / \mathrm{mL}$ of reduction, respectively) by LTP treatment in exposure times as low as $30 \mathrm{~s}$. Even without complete inactivation, $S$. mutans viability was also significantly reduced in both single- and multi-species biofilms. In conclusion, low exposure times of LTP affects single- and multi-species cariogenic biofilms, which makes LTP treatment a promising candidate to contribute to the development of new protocols for the treatment and control of dental caries.

Author Contributions: Conceptualization, C.Y.K.-I. and S.D.; methodology, C.Y.K.-I. and S.D.; formal analysis, L.W.F.; investigation, B.H.D.P. and L.W.F.; resources, S.D.; writing-original draft preparation, L.W.F.; writing—review and editing, B.H.D.P., S.D. and C.Y.K.-I.; supervision, S.D. and B.H.D.P.; project administration, S.D.; funding acquisition, C.Y.K.-I., L.W.F. and S.D. All authors have read and agreed to the published version of the manuscript. 
Funding: This research was funded by the São Paulo Research Foundation/FAPESP (Grants\# 2019/01676-4 and 2019/05856-7). This research was partially supported by the National Institute of Health/National Institute of Dental and Craniofacial Research (NIH/NIDCR-1R21DE028929-01).

Institutional Review Board Statement: Not applicable.

Informed Consent Statement: Not applicable.

Data Availability Statement: Data is contained within the article.

Conflicts of Interest: The authors declare no conflict of interest.

\section{References}

1. Narvai, P.C.; Frazão, P.; Roncalli, A.G.; Antunes, J.L.F. Cárie dentária no Brasil: Declínio, polarização, iniqüidade e exclusão social. Rev. Panam. Salud Pública 2006, 19, 385-393. [CrossRef] [PubMed]

2. Parisotto, T.M.; Steiner-Oliveira, C.; De Souza-E-Silva, C.M.; Peres, R.C.R.; Rodrigues, L.K.A.; Nobre-Dos-Santos, M. Assessment of cavitated and active non-cavitated caries lesions in 3- to 4-year-old preschool children: A field study. Int. J. Paediatr. Dent. 2011, 22, 92-99. [CrossRef] [PubMed]

3. So, M.; Ellenikiotis, Y.A.; Husby, H.M.; Paz, C.L.; Seymour, B.; Sokal-Gutierrez, K. Early Childhood Dental Caries, Mouth Pain, and Malnutrition in the Ecuadorian Amazon Region. Int. J. Environ. Res. Public Health 2017, 14, 550. [CrossRef]

4. Sutthavong, S.; Taebanpakul, S.; Kuruchitkosol, C.; Na Ayudhya, T.I.; Chantveerawong, T.; Fuangroong, S.; Cae-Ngow, S.; Rangsin, $\mathrm{R}$. Oral health status, dental caries risk factors of the children of public kindergarten and schools in Phranakornsriayudhya, Thailand. J. Med. Assoc. Thai 2010, 93, S71-S78. [PubMed]

5. De Freitas, M.T.M.; Soares, T.T.; Aragão, M.G.B.; Lima, R.A.; Duarte, S.; Zanin, I.C.J. Effect of Photodynamic Antimicrobial Chemotherapy on Mono- and Multi-Species Cariogenic Biofilms: A Literature Review. Photomed. Laser Surg. 2017, 35, 239-245. [CrossRef] [PubMed]

6. Pitts, N.B.; Zero, D.T.; Marsh, P.D.; Ekstrand, K.; Weintraub, J.A.; Ramos-Gomez, F.; Tagami, J.; Twetman, S.; Tsakos, G.; Ismail, A. Dental Caries. Nat. Rev. Dis. Primers 2017, 3, 1-16. [CrossRef] [PubMed]

7. Colombo, A.; Souto, R.M.D.; Da Silva-Boghossian, C.M.; Miranda, R.; Lourenço, T.G.B. Microbiology of Oral Biofilm-Dependent Diseases: Have We Made Significant Progress to Understand and Treat These Diseases? Curr. Oral Health Rep. 2014, 2, 37-47. [CrossRef]

8. Boles, B.R.; Thoendel, M.; Singh, P.K. Self-generated diversity produces "insurance effects" in biofilm communities. Proc. Natl. Acad. Sci. USA 2004, 101, 16630-16635. [CrossRef]

9. Sharma, D.; Misba, L.; Khan, A.U. Antibiotics versus biofilm: An emerging battleground in microbial communities. Antimicrob. Resist. Infect. Control 2019, 8, 1-10. [CrossRef]

10. Mah, T.-F. Biofilm-specific antibiotic resistance. Future Microbiol. 2012, 7, 1061-1072. [CrossRef]

11. Souza, J.C.M.; Mota, R.R.C.; Sordi, M.B.; Passoni, B.B.; Benfatti, C.A.M.; Magini, R.S. Biofilm Formation on Different Materials Used in Oral Rehabilitation. Braz. Dent. J. 2016, 27, 141-147. [CrossRef]

12. Arthur, R.; Waeiss, R.; Hara, A.; Lippert, F.; Eckert, G.; Zero, D. A Defined-Multispecies Microbial Model for Studying Enamel Caries Development. Caries Res. 2013, 47, 318-324. [CrossRef]

13. Klein, M.I.; Xiao, J.; Lu, B.; Delahunty, C.M.; Yates, J.R.; Koo, H. Streptococcus mutans Protein Synthesis during Mixed-Species Biofilm Development by High-Throughput Quantitative Proteomics. PLoS ONE 2012, 7, e45795. [CrossRef]

14. Gomar-Vercher, S.; Cabrera-Rubio, R.; Mira, A.; Montiel-Company, J.M.; Almerich-Silla, J.M. Relationship of children's salivary microbiota with their caries status: A pyrosequencing study. Clin. Oral Investig. 2014, 18, 2087-2094. [CrossRef]

15. Takahashi, N.; Nyvad, B. Caries Ecology Revisited: Microbial Dynamics and the Caries Process. Caries Res. 2008, 42, 409-418. [CrossRef] [PubMed]

16. Bowen, W. Do we need to be concerned about dental caries in the coming millennium? Crit. Rev. Oral Biol. Med. 2002, 13, 126-131. [CrossRef]

17. Leme, A.F.P.; Koo, H.; Bellato, C.M.; Bedi, G.; Cury, J.A. The Role of Sucrose in Cariogenic Dental Biofilm Formation-New Insight. J. Dent. Res. 2006, 85, 878-887. [CrossRef] [PubMed]

18. Marsh, P. Controlling the oral biofilm with antimicrobials. J. Dent. 2010, 38, S11-S15. [CrossRef]

19. Kreth, J.; Zhu, L.; Merritt, J.; Shi, W.; Qi, F. Role of sucrose in the fitness of Streptococcus mutans. Oral Microbiol. Immunol. 2008, 23, 213-219. [CrossRef] [PubMed]

20. Tenuta, L.M.A.; Cury, A.A.D.B.; Bortolin, M.C.; Vogel, G.L.; Cury, J.A. Ca, Pi, and F in the Fluid of Biofilm Formed under Sucrose. J. Dent. Res. 2006, 85, 834-838. [CrossRef]

21. Leme, A.F.P.; Dalcico, R.; Tabchoury, C.P.M.; Cury, A.A.D.B.; Rosalen, P.; Cury, J. In situ effect of frequent sucrose exposure on enamel demineralization and on plaque composition after APF application and F dentifrice use. J. Dent. Res. 2004, 83, 71-75. [CrossRef] [PubMed]

22. Rosan, B.; Lamont, R.J. Dental plaque formation. Microbes Infect. 2000, 2, 1599-1607. [CrossRef]

23. Nobbs, A.H.; Zhang, Y.; Khammanivong, A.; Herzberg, M.C. Streptococcus gordonii Hsa Environmentally Constrains Competitive Binding by Streptococcus sanguinis to Saliva-Coated Hydroxyapatite. J. Bacteriol. 2007, 189, 3106-3114. [CrossRef] [PubMed] 
24. Fachon-Kalweit, S.; Elder, B.L.; Fives-Taylor, P. Antibodies that bind to fimbriae block adhesion of Streptococcus sanguis to saliva-coated hydroxyapatite. Infect. Immun. 1985, 48, 617-624. [CrossRef]

25. Caufield, P.W.; Dasanayake, A.P.; Li, Y.; Pan, Y.; Hsu, J.; Hardin, J.M. Natural History of Streptococcus sanguinis in the Oral Cavity of Infants: Evidence for a Discrete Window of Infectivity. Infect. Immun. 2000, 68, 4018-4023. [CrossRef]

26. Li, Y.; Ge, Y.; Saxena, D.; Caufield, P.W. Genetic Profiling of the Oral Microbiota Associated with Severe Early-Childhood Caries. J. Clin. Microbiol. 2006, 45, 81-87. [CrossRef]

27. Sounah, S.A.; Madfa, A.A. Correlation between dental caries experience and the level of Streptococcus mutans and lactobacilli in saliva and carious teeth in a Yemeni adult population. BMC Res. Notes 2020, 13, 1-6. [CrossRef]

28. Becker, M.R.; Paster, B.J.; Leys, E.J.; Moeschberger, M.L.; Kenyon, S.G.; Galvin, J.L.; Boches, S.K.; Dewhirst, F.E.; Griffen, A.L. Molecular Analysis of Bacterial Species Associated with Childhood Caries. J. Clin. Microbiol. 2002, 40, 1001-1009. [CrossRef]

29. Lemos, J.A.; Palmer, S.; Zeng, L.; Wen, Z.; Kajfasz, J.; Freires, I.; Abranches, J.; Brady, L. The Biology of Streptococcus mutans. Microbiol. Spectr. 2019, 7. [CrossRef]

30. MacKenzie, L.; Banerjee, A. Minimally invasive direct restorations: A practical guide. Br. Dent. J. 2017, 223, 163-171. [CrossRef]

31. Frencken, J.E. Atraumatic restorative treatment and minimal intervention dentistry. Br. Dent. J. 2017, 223, 183-189. [CrossRef] [PubMed]

32. Uloopi, K.S.; Mohan, P.V.M.U.; Vinay, C.; Rao, R.C. In vivo comparison of cavity disinfection efficacy with APF gel, Propolis, Diode Laser, and 2\% chlorhexidine in primary teeth. Contemp. Clin. Dent. 2016, 7, 45-50. [CrossRef] [PubMed]

33. Ranjan, R.; Krishnamraju, P.V.; Shankar, T.; Gowd, S. Nonthermal Plasma in Dentistry: An Update. J. Int. Soc. Prev. Community Dent. 2017, 7, 71-75. [PubMed]

34. Yang, B.; Chen, J.; Yu, Q.; Li, H.; Lin, M.; Mustapha, A.; Hong, L.; Wang, Y. Oral bacterial deactivation using a low-temperature atmospheric argon plasma brush. J. Dent. 2011, 39, 48-56. [CrossRef]

35. Laroussi, M. Plasma Medicine: A Brief Introduction. Plasma 2018, 1, 47-60. [CrossRef]

36. Kong, M.G.; Kroesen, G.; Morfill, G.; Nosenko, T.; Shimizu, T.; Van Dijk, J.; Zimmermann, J.L. Plasma medicine: An introductory review. New J. Phys. 2009, 11. [CrossRef]

37. Bourke, P.; Ziuzina, D.; Han, L.; Cullen, P.; Gilmore, B.F. Microbiological interactions with cold plasma. J. Appl. Microbiol. 2017, 123, 308-324. [CrossRef]

38. Neyts, E.C.; Brault, P. Molecular Dynamics Simulations for Plasma-Surface Interactions. Plasma Process. Polym. 2017, 14, 1-2. [CrossRef]

39. Dezest, M.; Chavatte, L.; Bourdens, M.; Quinton, D.; Camus, M.; Garrigues, L.; Descargues, P.; Arbault, S.; Burlet-Schiltz, O.; Casteilla, L.; et al. Mechanistic insights into the impact of Cold Atmospheric Pressure Plasma on human epithelial cell lines. Sci. Rep. 2017, 7, 41163. [CrossRef]

40. Delben, J.A.; Zago, C.E.; Tyhovych, N.; Duarte, S.; Vergani, C.E. Effect of Atmospheric-Pressure Cold Plasma on Pathogenic Oral Biofilms and In Vitro Reconstituted Oral Epithelium. PLOS ONE 2016, 11, e0155427. [CrossRef]

41. Chiodi, B.A.; Lima, G.M.G.; Nishime, T.M.C.; Gontijo, A.V.L.; Kostov, K.G.; Koga-Ito, C.Y. Amplitude-modulated cold atmospheric pressure plasma jet for treatment of oral candidiasis: In vivo study. PLoS ONE 2018, 13, e0199832. [CrossRef]

42. Carreiro, A.F.; Delben, J.A.; Guedes, S.; Silveira, E.J.; Janal, M.N.; Vergani, C.E.; Pushalkar, S.; Duarte, S. Low-temperature plasma on peri-implant-related biofilm and gingival tissue. J. Periodontol. 2019, 90, 507-515. [CrossRef]

43. Goree, J.; Liu, B.; Drake, D.; Stoffels, E. Killing of S. mutans Bacteria Using a Plasma Needle at Atmospheric Pressure. IEEE Trans. Plasma Sci. 2006, 34, 1317-1324. [CrossRef]

44. Yamazaki, H.; Ohshima, T.; Tsubota, Y.; Yamaguchi, H.; Jayawardena, J.A.; Nishimura, Y. Microbicidal activities of low frequency atmospheric pressure plasma jets on oral pathogens. Dent. Mater. J. 2011, 30, 384-391. [CrossRef]

45. Delben, J.A.; Murata, R.M.; Wei, X.; Castro, M.L.; Assunção, W.G.; Da Silva, N.R.F.A.; Duarte, S. Low-Temperature Plasma: An Effective Approach Against Candida albicans Biofilm. Plasma Med. 2014, 4, 231-244. [CrossRef]

46. Yassin, S.A.; German, M.J.; Rolland, S.; Rickard, A.H.; Jakubovics, N. Inhibition of multispecies biofilms by a fluoride-releasing dental prosthesis copolymer. J. Dent. 2016, 48, 62-70. [CrossRef]

47. Marsh, P.D. Sugar, fluoride, pH and microbial homeostasis in dental plaque. Proc. Finn. Dent. Soc. 1991, 87, 515-525.

48. Balaji, S. Dental caries: Research perspective. Indian J. Dent. Res. 2018, 29, 3. [CrossRef]

49. Xu, X.; Chen, F.; Huang, Z.; Ma, L.; Chen, L.; Pan, Y.; Xu, J.; Kim, S.; Kinane, D.; Koo, H.; et al. Meeting report: A close look at oral biofilms and microbiomes. Int. J. Oral Sci. 2018, 10, 1-5. [CrossRef]

50. Koo, H.; Falsetta, M.L.; Klein, M.I. The exopolysaccharide matrix: A virulence determinant of cariogenic biofilm. J. Dent. Res. 2013, 92, 1065-1073. [CrossRef]

51. Liu, T.; Wu, L.; Babu, J.P.; Hottel, T.L.; Garcia-Godoy, F.; Hong, L. Effects of atmospheric non-thermal argon/oxygen plasma on biofilm viability and hydrophobicity of oral bacteria. Am. J. Dent. 2017, 30, 52-56.

52. Hirano, Y.; Hayashi, M.; Tamura, M.; Yoshino, F.; Yoshida, A.; Masubuchi, M.; Imai, K.; Ogiso, B. Singlet oxygen generated by a new nonthermal atmospheric pressure air plasma device exerts a bactericidal effect on oral pathogens. J. Oral Sci. 2019, 61, 521-525. [CrossRef]

53. Wright, C.J.; Burns, L.H.; Jack, A.A.; Back, C.R.; Dutton, L.C.; Nobbs, A.H.; Lamont, R.J.; Jenkinson, H.F. Microbial interactions in building of communities. Mol. Oral Microbiol. 2013, 28, 83-101. [CrossRef] 
54. Dû, L.D.; Kolenbrander, P.E. Identification of Saliva-Regulated Genes of Streptococcus gordonii DL1 by Differential Display Using Random Arbitrarily Primed PCR. Infect. Immun. 2000, 68, 4834-4837. [CrossRef]

55. Gorynia, S.; Koban, I.; Matthes, R.; Welk, A.; Gorynia, S.; Hübner, N.-O.; Kocher, T.; Kramer, A. In vitro efficacy of cold atmospheric pressure plasma on S. sanguinis biofilms in comparison of two test models. GMS Hyg. Infect. Control 2013, 8. [CrossRef]

56. Bik, E.M.; Long, C.D.; Armitage, G.C.; Loomer, P.; Emerson, J.; Mongodin, E.F.; Nelson, K.E.; Gill, S.R.; Fraser-Liggett, C.M.; Relman, D.A. Bacterial diversity in the oral cavity of 10 healthy individuals. ISME J. 2010, 4, 962-974. [CrossRef]

57. Belda-Ferre, P.; Alcaraz, L.D.; Cabrera-Rubio, R.; Romero, H.; Simón-Soro, A.; Pignatelli, M.; Mira, A. The oral metagenome in health and disease. ISME J. 2011, 6, 46-56. [CrossRef]

58. Aas, J.A.; Paster, B.J.; Stokes, L.N.; Olsen, I.; Dewhirst, F.E. Defining the Normal Bacterial Flora of the Oral Cavity. J. Clin. Microbiol. 2005, 43, 5721-5732. [CrossRef]

59. Wyganowska-Swiatkowska, M.; Kotwicka, M.; Urbaniak, P.; Nowak, A.; Skrzypczak-Jankun, E.; Jankun, J. Clinical implications of the growth-suppressive effects of chlorhexidine at low and high concentrations on human gingival fibroblasts and changes in morphology. Int. J. Mol. Med. 2016, 37, 1594-1600. [CrossRef]

60. McBain, A.J.; Bartolo, R.G.; Catrenich, C.E.; Charbonneau, D.; Ledder, R.G.; Gilbert, P. Effects of a Chlorhexidine GluconateContaining Mouthwash on the Vitality and Antimicrobial Susceptibility of In Vitro Oral Bacterial Ecosystems. Appl. Environ. Microbiol. 2003, 69, 4770-4776. [CrossRef] [PubMed]

61. Sreenivasan, P.K.; Gittins, E. The effects of a chlorhexidine mouthrinse on culturable microorganisms of the tongue and saliva. Microbiol. Res. 2004, 159, 365-370. [CrossRef] [PubMed]

62. Vitkov, L.; Hermann, A.; Krautgartner, W.; Herrmann, M.; Fuchs, K.; Klappacher, M.; Hannig, M. Chlorhexidine-induced ultrastructural alterations in oral biofilm. Microsc. Res. Tech. 2005, 68, 85-89. [CrossRef]

63. Zanatta, F.B.; Antoniazzi, R.P.; Rösing, C.K. The Effect of $0.12 \%$ Chlorhexidine Gluconate Rinsing on Previously Plaque-Free and Plaque-Covered Surfaces: A Randomized, Controlled Clinical Trial. J. Periodontol. 2007, 78, 2127-2134. [CrossRef]

64. Flemming, H.-C.; Wingender, J. The biofilm matrix. Nat. Rev. Genet. 2010, 8, 623-633. [CrossRef]

65. Duarte, S.; Panariello, B.H.D. Comprehensive biomedical applications of low temperature plasmas. Arch. Biochem. Biophys. 2020, 693, 108560. [CrossRef] 